\title{
O som do silêncio (Paul Simon)*
}

\author{
Vanessa R. Lea** \\ The joy of sex. Alex Comfort (1972). \\ Sexo: algo apetitoso (síntese da \\ perspectiva Mebengokre)
}

Em primeiro lugar quero abordar o relativo silêncio sobre a questão da sexualidade na etnologia indígena. Ao começar a abordar esse tema, na década de 1980, fui censurada por uma colega mais velha; argumentou que não se escreve sobre determinadas coisas. Em outras palavras, no mundo acadêmico se trata, em parte, de uma questão geracional. Sexualidade somente se tornou digno de discussão, na etnologia indígena amazônica, no fim do século XX (o livro de Gregor [1985] sendo pioneiro, além de Seeger [1981:cap.6]). Anteriormente sexualidade era trancada numa espécie de redoma da intimidade - sinônimo de privacidade.

Relacionada ao silêncio é a questão da ética, algo que reverbera cada vez mais na academia. Ao iniciar minhas pesquisas no Brasil Central, no fim da década de 1970, assuntos relacionados a sexo constituíam um dos temas prediletos das mulheres Mebengokre (Kayapó). No entanto, ao retornar ao campo, em 1994, fui censurada pelos homens ao me ouvirem conversando com algumas mulheres sobre a prática do estiramento dos pequenos lábios, um sinal de apreciação sexual masculina. Rotularam o assunto como "fofoca", por não estar vinculado à geração de empregos nem salários. Ou seja, nas

\footnotetext{
Recebido para publicação em 7 de setembro de 2013, aceito em 15 de outubro de 2013. Agradeço as sugestões e copidescagem de Uirá Felippe Garcia (pós-doutorando no DA Unicamp), além dos comentários e troca de ideias com Cris Crocker, Paride Bollettin e diversos outros etnólogos ao longo dos anos.

** Professora Titular do Departamento de Antropologia do IFCH, Unicamp. vanessa.r.lea@gmail.com
}

cadernos pagu (41), julho-dezembro de 2013:87-93. 
últimas décadas houve uma reformulação do que seja pesquisa etnológica, concebida pelos índios atualmente como assessoria na elaboração e/ou gestão de projetos de desenvolvimento comunitário, educação ou saúde (um bom exemplo sendo a pesquisa de Marta Maria do Amaral Azevedo [cf CV Lattes] sobre saúde reprodutiva de mulheres indígenas no alto Rio Negro).

A necessidade de acomodar-se ao mundo não-indígena atiça a curiosidade dos povos indígenas a respeito da sociedade envolvente. Os índios compram DVDs pornográficos, assistidos por homens, mulheres e crianças. Trata-se de uma espécie de antropologia reversa que, como as telenovelas, permitem os indígenas investigarem o mundo dos brancos. Sexo oral e sexo anal são considerados animalescos, e os Mebengokre usam o verbo "chupar" ou "amamentar" (kaô) para descrever o costume, igualmente exótico, do beijo. A aquisição de dinheiro permite alguns homens experimentar os serviços de prostitutas nas cidades às quais têm acesso. Soube que (pelo menos em Mato Grosso) os clientes indígenas fazem sucesso entre as prostitutas; não chegam com problemas de culpa, inexiste um antes e depois. Gozam rapidamente, pagam o que devem e vão embora. Os homens ficam intrigados pelo fato de as mulheres brancas se mexerem durante o ato sexual e há cada vez mais interesse por parte de mulheres não-indígenas de experimentar sexo com um homem indígena. Os estereótipos do amante latino no norte da Europa e da sensualidade da mulata começam a ser complementados por aquele do índio musculoso, "sarado" por sua interação com a "natureza" na imaginação não-indígena.

Num dos cursos que ministrei para professores e líderes indígenas, tentei abordar a questão da homossexualidade, pensando que deveria prepará-los a adotar atitudes politicamente corretas no cenário intercultural. Retrucaram sumariamente que isso era problema de branco e recusaram perder tempo com esse tema. Sabemos pela pesquisa de Roscoe (1998) que a figura do bardache ou transexual era bastante disseminada entre os povos indígenas da América do Norte, mas na área do meu campo é tabu. 
Já escrevi alhures sobre o fato de os homens indígenas precisarem retribuir as mulheres pelo ato sexual. Minha impressão é que a virilidade, do ponto de vista deles, implica em gozar o mais rapidamente possível - uma espécie de gol sexual. Isso nos leva a uma das controvérsias relativas à sexualidade indígena. Bamberger (1974) escreveu sobre algo que ela denomina estupro coletivo (gang rape) entre os Mebengokre, um fenômeno descrito por William e Jean Crocker (1994), relativo a outro povo Jê, como sexo seriado consentido com vários homens. Esse autor argumenta que isso poderia proporcionar prazer às mulheres, compensando a rapidez individual. Ocorre no decorrer de determinadas cerimônias $e$ acabei concluindo que se trata de uma espécie de rito de fertilidade. As mulheres mais velhas me descreveram isso como algo que se faz em benefício de sobrinhos ou netos (de ambos os sexos), com um ar de cumplicidade. Parece ser mais assustador quando se trata de moças cujos cabelos são cortados para ajudar o milho a crescer. Algumas delas são elegidas para terem relações sexuais com um grupo de homens. Os índios percebem que os brancos censuram tais práticas, evitam falar sobre o assunto e mantêm tais atos longe dos olhares curiosos dos brancos.

Às vezes, a academia promove uns debates mirabolantes; um deles diz respeito à suposta "especialista sexual paga" (me kupry), a que se refere Dennis Werner (1985) numa pesquisa sobre os Mebengokre. Esse autor confunde a noção de pessoas desposáveis, porque não casados, com uma espécie de prostituta. Essa questão conseguiu espaço num artigo sobre gênero na Amazônia na conceituada revista L'Homme em Paris, no qual Irène Bellier (1993) expressou surpresa perante tal fenômeno numa sociedade tida como igualitária.

Não há espaço aqui para abordar adequadamente a questão da assimetria entre o mundo indígena feminino $e$ o masculino. Aliás inexiste tal categoria. Há tanta diversidade entre os povos desse continente quanto entre os povos africanos, algo frequentemente ignorado. Muitos autores apelam à noção de complementaridade entre os dois sexos, algo que me parece não 
resolver esse debate. Os Mebengokre interpretam o dimorfismo sexual como um principium divisionis, para usar uma expressão proveniente de Bourdieu (1977:112). Os homens são designados como a coletividade com pênis e a primeira coisa que se pergunta quando nasce um bebê é se é macho ou fêmea. Essa dicotomia é reforçada entre muitos povos indígenas em aspectos diferenciados da fala de homens e de mulheres. Fui regularmente criticada por usar expressões masculinas na língua mebengokre, sendo comparada, nesse aspecto, a uma missionária que havia convivido com eles.

A complementaridade entre os sexos é reforçada pela divisão sexual de trabalho, algo que Lévi-Strauss (1977) e, posteriormente, Héritier (1979 e passim) descreveram apropriadamente como um contrato de sustento mútuo, de conteúdo arbitrário. É algo que pode ser exacerbado pela aquisição de dinheiro, muitas vezes monopolizada pelos homens.

Na minha experiência, a questão da relação entre homens e mulheres interessa aos intelectuais indígenas cada vez mais, porém, sem deslancharem para a distinção entre sexo e gênero. Aliás, os meios de comunicação de massa frequentemente confundem tal distinção. Um dos focos atuais dos movimentos indígenas, associado ao discurso pós-colonial, é uma reflexão crítica sobre patriarcalismo.

Do meu ponto de vista, gênero é uma categoria imprescindível para analisar as ditas sociedades indígenas. A noção de "contato" já foi substituída pela interpretação das transformações em curso globalmente. O temor de um mundo homogêneo também perdeu terreno. Um dos dilemas atuais é a conciliação do universal com o local. Agências de desenvolvimento e de direitos humanos, como a UNESCO, promulgam, ingenuamente, valores supostamente universais (hegemônicos no "Ocidente") que muitas vezes entram em choque com valores locais. As sociedades indígenas estão cada vez mais críticas de tais imposições. Isso torna inteligível o silêncio dos etnólogos com respeito a práticas condenadas pela sociedade 
nacional e pelas igrejas, tais como poligamia, a criação de futuros cônjuges desde a infância, gravidez na adolescência, a prevalência de relações sexuais extraconjugais, trocas sexuais entre casais e/ou entre categorias de idade.

$\mathrm{Na}$ década de 1980, antropólogas interessadas em questões de gênero começaram a reivindicar atenção para a perspectiva das mulheres versus aquela dos homens. Atualmente, há grandes divisões geracionais que impossibilitam uma dicotomia referente à visão de homens e de mulheres. Pessoas mais velhas podem valorizar tradições como casamentos arranjados. Um dos casamentos mais bem sucedidos no meu campo era de um homem e a mulher que ele raptara numa expedição guerreira. No entanto, os jovens reivindicam casamentos que imitam o amor romântico dos brancos, elegendo seus próprios cônjuges. Os afetos e o prazer sexual poderiam ser considerados, pelo menos parcialmente, como subprodutos do indivíduo moderno e da valorização do indivíduo analisados por Dumont (1966, 1985). Os velhos querem aumentar a população para compensar as perdas ocasionadas pelas doenças dos brancos e, entre os Mebengokre, feminilidade é indissociável de maternidade e da criação dos germanos mais jovens, filhos e netos. Algo que está produzindo mudanças significativas são os casamentos interétnicos, não necessariamente com não indígenas, mas entre indivíduos provenientes de povos distintos. É um tema que merece ser melhor aprofundado.

Nas últimas décadas do século XX, me chamou atenção que sessões de pintura corporal entre mulheres nuas eram algo totalmente desprovido de erotismo. Hoje em dia, as brancas são pintadas de calcinha e sutiã. Os homens não Mebengokre há décadas substituíram o estojo peniano pelos shorts. Num congresso recente, em Belém, achei curiosamente "não gramatical" o fato de as mulheres Mebengokre dançarem para uma plateia de não índios vestidas de calcinhas. Do ponto de vista dos índios elas estavam vestidas, uma ressignificação interessante de roupas íntimas. Soube que, no Alto Xingu, os homens 
O som do silêncio

começaram a discutir quais ângulos femininos podem ser fotografados por visitantes masculinos dos povos vizinhos sem serem indecorosos. Os etnólogos se deram conta de que a falta de um determinado termo ou expressão (como família nuclear ou núcleo endogâmico) não significa que tal configuração inexista. $\mathrm{O}$ fato de não ter algo que traduz como gênero, sexualidade ou erotismo nas línguas indígenas não significa que os povos indígenas sejam alheios a tais questões. Em algumas aldeias Mebengokre já se realizam desfiles à procura da "Miss Kayapó". Enfim os povos indígenas não se limitam a reproduzir suas tradições; interagem entre si e com outros povos de forma criativa. A diversidade humana não está estanque e inexiste uma mão invisível que permite prever a multiplicidade de suas trajetórias futuras.

\section{Referências bibliográficas}

BAMBERGER, Joan. The myth of matriarchy: why men rule in primitive society. In: ROSALDO, M. and LAMPHERE, L. (orgs.) Women, Culture and Society. L. Stanford, University Press, 1974.

BELLIER, Irène. Reflexions sur la question du genre dans les sociétés amazoniennes. L'Homme XXXIII n ${ }^{\circ} 126-128,1993$, pp.517-526.

BourdiEU, P. Outline of a theory of practice. Cambridge, Cambridge University Press, 1977.

CROCKER, W.H. e CROCKER, J. The Canela: Bonding through Kinship, Ritual, and Sex. Fort Worth, Harcourt Brace College Publishers, 1994.

DumONT, Louis. Homo Hierarchicus. Paris, Gallimard, 1979 [1966].

O Individualismo: Perspectiva Antropológica da Ideologia Moderna. Rio de Janeiro, Rocco, 1985.

Gregor, T. Anxious Pleasures: The sexual lives of an Amazonian People. Chicago, University of Chicago Press, 1985.

HÉRITIER, Françoise. Enciclopédia einaudi 20. Parentesco. 'Parentesco'. Lisboa, Imprensa Nacional/Casa da Moeda, 1989 [1979]. 
LÉVI-STRAUSS, Claude. A família. In: LÉVI-STRAUSS et al. A família como instituição. Porto, Rés, 1977, pp.5-43.

Roscoe, W. Changing Ones: Third and Fourth Genders in Native North America. New York, St. Martin's Griffin, 1998.

SEEGER, Anthony. Nature and Society in Central Brazil: The Suyá Indians of Mato Grosso. Cambridge MA.,Harvard Univ. Press, 1981.

WeRnER, Dennis. Paid sex specialists among the Mekranoti. Journal of Anthropological Research 40 (3), 1985, pp.394-405. 